\title{
A comparison of the degree of damage caused by three species of slugs Arion vulgaris, Arion rufus and Deroceras reticulatum on seven cultivars of yellow lupine (Lupinus luteus L.)
}

\section{Porównanie stopnia uszkodzeń różnych odmian łubinu żółtego (Lupinus luteus L.) przez trzy gatunki ślimaków nagich Arion vulgaris, Arion rufus i Deroceras reticulatum}

\author{
Jan Kozłowski $^{1 *}$, Monika Jaskulska ${ }^{1}$, Maria Kozłowska ${ }^{2}$
}

\begin{abstract}
Summary
We studied in laboratory conditions the degree of damage on seven yellow lupine cultivars caused by the slugs Arion vulgaris, Arion rufus and Deroceras reticulatum. The tests without choice were performed on plants at the growth stage of 2-3 leaves, which were exposed to slug grazing. Significant differences in the degree of damage resulting from slug feeding were found on some of the yellow lupine cultivars. A. vulgaris damaged plants of the Dukat cultivar the least as compare to the Lord cultivar, while for $A$. rufus the results were opposite. The degree of plant damage caused by $D$. reticulatum was similar for all yellow lupine cultivars. It was shown that the sensitivity of yellow lupine cultivars to damage caused by $A$. vulgaris and $A$. rufus is diverse and specific to those slug species, and affected by their different food preferences.
\end{abstract}

Key words: slugs; cultivars of yellow lupine; damage

\section{Streszczenie}

W warunkach laboratoryjnych przeprowadzono badania nad wielkością uszkodzeń roślin siedmiu odmian łubinu żółtego przez ślimaki nagie Arion vulgaris, Arion rufus i Deroceras reticulatum. Testy bez wyboru wykonano na roślinach w fazie 2-3 liści właściwych, które eksponowano na żerowanie ślimaków. Stwierdzono istotne różnice w wielkościach uszkodzeń roślin niektórych odmian łubinu przez ślimaki. A. vulgaris najsłabiej uszkadzał rośliny łubinu odmiany Dukat w porównaniu do roślin łubinu odmiany Lord, natomiast A. rufus, odwrotnie. Stopień uszkodzenia roślin wszystkich odmian łubinu żółtego przez $D$. reticulatum był podobny. Wykazano, że wrażliwość odmian łubinu żółtego na uszkodzenia przez ślimaki $A$. vulgaris i $A$. rufus jest zróżnicowana i specyficzna dla tych gatunków ślimaków, co wynika z ich różnych preferencji pokarmowych.

Słowa kluczowe: ślimaki; odmiany łubinu żółtego; uszkodzenia

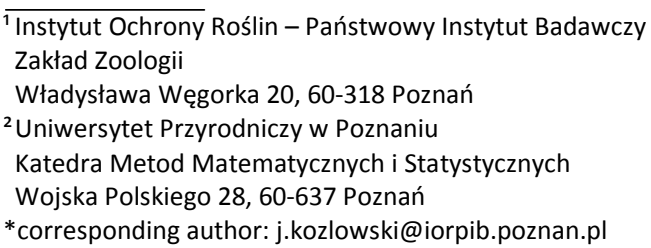




\section{Wstęp / Introduction}

Łubin żółty (Lupinus luteus L.) jest w ostatnich latach coraz częściej uszkadzany przez różne gatunki ślimaków nagich. Największe szkody w uprawach łubinów i innych roślin $\mathrm{z}$ rodziny bobowatych, zwłaszcza we wczesnych fazach ich rozwoju, wyrządza obcy, inwazyjny ślimak Arion vulgaris Moquin Tandon, 1885 oraz Arion rufus (Linnaeus, 1758) i Deroceras reticulatum (O.F. Müller, 1774) (South 1992; Ferguson 1994). Obok nich, w uprawach łubinów występują niekiedy inne śliniki (Arionidae) oraz pomrowiki (Agriolimacidae) lub pomrowy (Limacidae), jednak szkody przez nie wyrządzane nie są zbyt duże. Ślimaki mają szeroki zakres roślin żywicielskich, jednak stopień uszkodzeń gatunków i odmian roślin przez poszczególne ślimaki jest zróżnicowany (Byers 2002; Barlow i wsp. 2013). Przyczyną tego są różne wymagania pokarmowe ślimaków oraz odmienna reakcja na fizyczne i chemiczne właściwości roślin, specyficzne dla poszczególnych odmian. Większość dotychczasowych badań nad uszkodzeniami roślin łubinów przez ślimaki dotyczyła gorzkich i słodkich odmian łubinu wąskolistnego (Lupinus angustifolius L.), których stopień uszkodzenia jest uzależniony od poziomu zawartości alkaloidów (Wink 1984; Carey i Wink 1994; Aguiar i Wink 1999; Chevalier i wsp. 2000).

W badaniach skupiono się na ocenie wielkości uszkodzeń niskoalkaloidowych odmian łubinu żółtego przez różne gatunki ślimaków, w celu wyodrębnienia odmian wrażliwych i tolerancyjnych na ich żerowanie.

\section{Materiały i metody / Materials and methods}

W badaniach wykorzystano trzy gatunki ślimaków: A. vulgaris, A. rufus i $D$. reticulatum oraz rośliny siedmiu odmian łubinu żółtego (L. luteus), wpisanych do krajowego rejestru (KR) w Polsce. Według danych opracowanych przez Centralny Ośrodek Badania Odmian Roślin Uprawnych, zawartość alkaloidów w roślinach badanych odmian wynosi od 0,015 do $0,023 \%$ s.m. (Domański i Osiecka 2014). Wylęgnięte, kilkudniowe ślimaki zebrano z ogrodów w okolicy Poznania i Wronek, z trzech stanowisk, w których wcześniej zidentyfikowano dorosłe ślimaki. Zebrane ślimaki umieszczono na podłożu ziemi w plastikowych pojemnikach i hodowano przez trzy miesiące $\mathrm{w}$ temperaturze $16^{\circ} \mathrm{C}$. Dwa razy w tygodniu ślimakom podawano i wymieniano pokarm, który zawierał: liście kapusty, bulwy ziemniaków, korzenie marchwi oraz otręby pszenne $\mathrm{z}$ dodatkiem węglanu wapnia. Przed doświadczeniami ślimaki przez 48 godzin głodzono, a następnie ważono. Nasiona łubinów wysiano w skrzynkach ogrodniczych wypełnionych ziemią, w szklarni Instytutu Ochrony Roślin - Państwowego Instytutu Badawczego w Poznaniu i uprawiano do uzyskania roślin w fazie 2-3 liści właściwych, które wykorzystano w doświadczeniach.

Doświadczenia założono w układzie całkowicie losowym, dla każdej kombinacji zastosowano pięć powtórzeń (pojemników). Rośliny posadzono w gliniasto-próchnicznej ziemi, w 105 plastikowych, zamykanych pojemni- kach $(26 \times 26 \times 14 \mathrm{~cm})$, zaopatrzonych w otwory wentylacyjne. W każdym pojemniku posadzono po pięć roślin jednej odmiany. Po dwóch dniach w pojemnikach umieszczono po jednym osobniku ślimaka o średniej masie: A. vulgaris $-1,25 \mathrm{~g}$, A. rufus $-1,24 \mathrm{~g}$ i $D$. reticulatum - 0,44 g. Badania wykonano w kabinie klimatycznej, w temperaturze $17^{\circ} \mathrm{C}$, wilgotności powietrza (RH) $73 \pm 3 \%$ i długości dnia 12 godzin. Obserwacje prowadzono co dwa dni, określając stopień uszkodzenia roślin według pięciostopniowej skali $(0 ; 25 ; 50 ; 75$ i 100\% uszkodzonej powierzchni roślin). Na zakończenie badań ślimaki powtórnie ważono. Uzyskane wyniki obserwacji poddano analizie wariancji i zastosowano test Fishera przy poziomie istotności $\alpha=0,05$.

\section{Wyniki i dyskusja / Results and discussion}

Analiza wielkości uszkodzeń roślin przez ślimaki A. vulgaris i $A$. rufus w kolejnych dniach ich żerowania, wykazała istotne różnice między niektórymi odmianami. Po 24 godzinach, najsłabiej uszkodzone przez A. vulgaris były rośliny łubinu odmiany Dukat i Parys, a najsilniej rośliny odmiany Lord (tab. 1). Od trzeciego dnia, istotnie słabiej uszkodzone były rośliny odmiany Dukat w porównaniu do roślin odmiany Baryt, a od czwartego dnia, także w porównaniu do roślin odmiany Lord, które były najsilniej uszkadzane przez tego ślimaka. Po siedmiu dniach żerowania $A$. vulgaris, uszkodzenia roślin wahały się od $34 \%$ dla łubinu odmiany Dukat do $62 \%$ dla łubinu odmiany Lord.

A. rufus, po jednym dniu żerowania, istotnie słabiej uszkodził rośliny łubinu odmiany Lord i Taper niż rośliny odmiany Perkoz (tab. 2). Od drugiego do szóstego dnia obserwacji, istotnie słabiej uszkadzane przez tego ślimaka były rośliny łubinu odmiany Lord, a po pięciu dniach także rośliny odmiany Baryt, w porównaniu do uszkodzeń roślin odmiany Dukat. Po siedmiu dniach, istotnie słabiej uszkodzone były rośliny odmiany Parys (35\%), w porównaniu do uszkodzeń roślin odmiany Dukat $(55 \%)$. Słabo uszkodzone były także rośliny odmiany Lord (37\%), jednak różnic istotnych w stosunku do uszkodzeń roślin odmiany Dukat nie wykazano. W przypadku D. reticulatum, stopień uszkodzenia roślin badanych odmian był podobny (tab. 3). Wyjątek stanowiły rośliny odmiany Mister, które były silniej uszkodzone od roślin pozostałych odmian, po 3, 6 i 7 dniach żerowania tego ślimaka.

Po siedmiu dniach żerowania badanych gatunków ślimaków, łącznie dla roślin wszystkich odmian łubinu, stwierdzono istotną zależność między ilością zjedzonego pokarmu a przyrostem masy ich ciała. Współczynniki korelacji i poziom istotności tego związku dla poszczególnych gatunków wynosiły: A. vulgaris $\mathrm{r}=0,3728$, $\mathrm{p}=0,0150 ; A$. rufus $\mathrm{r}=0,5920, \mathrm{p}=0,00004 ; D$. reticulatum $\mathrm{r}=0,4579, \mathrm{p}=0,0023$. Sugeruje to, że rośliny łubinu żółtego były odpowiednim źródłem pokarmu w okresie siedmiu dni żerowania ślimaków wyłącznie na tych roślinach.

Uzyskane wyniki wskazują, że wrażliwość niektórych odmian łubinu żółtego na uszkodzenia przez ślimaki jest zróżnicowana. Przyczyną tego jest prawdopodobnie od- 
Tabela 1. Tempo i wielkość uszkodzeń odmian Lupinus luteus przez Arion vulgaris i wyniki testu Fischera przy $\alpha=0,05$

Table 1. The rate and size of damage to cultivars of Lupinus luteus caused by Arion vulgaris and results of Fisher's test for $\alpha=0.05$

\begin{tabular}{l|c|c|c|c|c|c|c}
\hline \multirow{2}{*}{$\begin{array}{c}\text { Odmiana } \\
\text { Cultivar }\end{array}$} & \multicolumn{9}{c}{$\begin{array}{c}\text { Dni żerowania ślimaków } \\
\text { Duration of slugs feeding in days }\end{array}$} \\
\cline { 2 - 10 } & 1 & 2 & 3 & 4 & 5 & 6 & 7 \\
\hline Dukat & $4,2 \mathrm{a}$ & $8,3 \mathrm{a}$ & $11,7 \mathrm{a}$ & $16,7 \mathrm{a}$ & $24,2 \mathrm{a}$ & $30,0 \mathrm{a}$ & $34,2 \mathrm{a}$ \\
\hline Lord & $9,2 \mathrm{~b}$ & $13,2 \mathrm{a}$ & $21,7 \mathrm{ab}$ & $31,7 \mathrm{bc}$ & $44,2 \mathrm{c}$ & $50,8 \mathrm{~b}$ & $61,7 \mathrm{~b}$ \\
\hline Parys & $4,2 \mathrm{a}$ & $9,2 \mathrm{a}$ & $14,2 \mathrm{ab}$ & $19,2 \mathrm{ab}$ & $26,7 \mathrm{ab}$ & $34,2 \mathrm{ab}$ & $44,2 \mathrm{ab}$ \\
\hline Taper & $8,3 \mathrm{ab}$ & $15,8 \mathrm{a}$ & $20,8 \mathrm{ab}$ & $30,0 \mathrm{bc}$ & $40,0 \mathrm{abc}$ & $46,7 \mathrm{ab}$ & $55,0 \mathrm{~b}$ \\
\hline Mister & $5,8 \mathrm{ab}$ & $9,2 \mathrm{a}$ & $21,7 \mathrm{ab}$ & $25,8 \mathrm{abc}$ & $35,0 \mathrm{abc}$ & $40,0 \mathrm{ab}$ & $46,7 \mathrm{ab}$ \\
\hline Perkoz & $5,8 \mathrm{ab}$ & $11,7 \mathrm{a}$ & $21,7 \mathrm{ab}$ & $29,2 \mathrm{abc}$ & $36,7 \mathrm{abc}$ & $44,2 \mathrm{ab}$ & $55,0 \mathrm{~b}$ \\
\hline Baryt & $5,8 \mathrm{ab}$ & $16,7 \mathrm{a}$ & $24,2 \mathrm{~b}$ & $32,5 \mathrm{c}$ & $41,7 \mathrm{bc}$ & $50,0 \mathrm{~b}$ & $55,0 \mathrm{~b}$ \\
\hline
\end{tabular}

Wartości w kolumnach oznaczone tą samą literą nie różnią się istotnie - Values in columns marked with the same letters do not differ significantly

Tabela 2. Tempo i wielkość uszkodzeń odmian Lupinus luteus przez Arion rufus i wyniki testu Fischera przy $\alpha=0,05$

Table 2. The rate and size of damage to cultivars of Lupinus luteus caused by Arion rufus and results of Fisher's test for $\alpha=0.05$

\begin{tabular}{l|c|c|c|c|c|c|c}
\hline \multirow{2}{*}{$\begin{array}{c}\text { Odmiana } \\
\text { Cultivar }\end{array}$} & \multicolumn{7}{c}{$\begin{array}{c}\text { Dni żerowania ślimaków } \\
\text { Duration of slugs feeding in days }\end{array}$} \\
\cline { 2 - 9 } & 1 & 2 & 3 & 4 & 5 & 6 & 7 \\
\hline Dukat & $6,7 \mathrm{ab}$ & $15,8 \mathrm{c}$ & $24,2 \mathrm{~b}$ & $34,2 \mathrm{~b}$ & $40,8 \mathrm{bc}$ & $47,5 \mathrm{~b}$ & $55,0 \mathrm{~b}$ \\
\hline Lord & $2,5 \mathrm{a}$ & $5,0 \mathrm{a}$ & $10,0 \mathrm{a}$ & $14,2 \mathrm{a}$ & $22,5 \mathrm{a}$ & $30,0 \mathrm{a}$ & $36,7 \mathrm{ab}$ \\
\hline Parys & $5,8 \mathrm{ab}$ & $10,8 \mathrm{abc}$ & $15,0 \mathrm{ab}$ & $20,8 \mathrm{a}$ & $27,5 \mathrm{abc}$ & $30,8 \mathrm{ab}$ & $35,0 \mathrm{a}$ \\
\hline Taper & $2,5 \mathrm{a}$ & $5,8 \mathrm{ab}$ & $10,8 \mathrm{a}$ & $17,5 \mathrm{a}$ & $26,7 \mathrm{ab}$ & $33,3 \mathrm{ab}$ & $39,2 \mathrm{ab}$ \\
\hline Mister & $4,2 \mathrm{ab}$ & $8,3 \mathrm{ab}$ & $14,2 \mathrm{a}$ & $19,2 \mathrm{a}$ & $27,5 \mathrm{abc}$ & $31,7 \mathrm{ab}$ & $38,3 \mathrm{ab}$ \\
\hline Perkoz & $8,3 \mathrm{~b}$ & $11,7 \mathrm{bc}$ & $19,2 \mathrm{ab}$ & $20,2 \mathrm{a}$ & $28,3 \mathrm{abc}$ & $34,2 \mathrm{ab}$ & $39,2 \mathrm{ab}$ \\
\hline Baryt & $3,3 \mathrm{ab}$ & $9,2 \mathrm{ab}$ & $18,3 \mathrm{ab}$ & $24,2 \mathrm{ab}$ & $41,7 \mathrm{c}$ & $44,2 \mathrm{ab}$ & $49,2 \mathrm{ab}$ \\
\hline
\end{tabular}

Wartości w kolumnach oznaczone tą samą literą nie różnią się istotnie - Values in columns marked with the same letters do not differ significantly

Tabela 3. Tempo i wielkość uszkodzeń odmian Lupinus luteus przez Deroceras reticulatum i wyniki testu Fischera przy $\alpha=0,05$

Table 3. The rate and size of damage to cultivars of Lupinus luteus caused by Deroceras reticulatum and results of Fisher's test for $\alpha=0.05$

\begin{tabular}{l|c|c|c|c|c|c|c}
\hline \multirow{2}{*}{$\begin{array}{c}\text { Odmiana } \\
\text { Cultivar }\end{array}$} & \multicolumn{7}{c}{$\begin{array}{c}\text { Dni żerowania ślimaków } \\
\text { Duration of slugs feeding in days }\end{array}$} \\
\cline { 2 - 9 } & 1 & 2 & 3 & 4 & 5 & 6 & 7 \\
\hline Dukat & $3,3 \mathrm{a}$ & $4,2 \mathrm{a}$ & $5,0 \mathrm{a}$ & $6,7 \mathrm{a}$ & $9,2 \mathrm{a}$ & $12,5 \mathrm{a}$ & $13,3 \mathrm{a}$ \\
\hline Lord & $2,5 \mathrm{a}$ & $7,5 \mathrm{a}$ & $12,5 \mathrm{ab}$ & $16,7 \mathrm{a}$ & $18,3 \mathrm{a}$ & $19,2 \mathrm{ab}$ & $19,2 \mathrm{ab}$ \\
\hline Parys & $3,3 \mathrm{a}$ & $5,8 \mathrm{a}$ & $10,0 \mathrm{ab}$ & $10,0 \mathrm{a}$ & $10,0 \mathrm{a}$ & $13,3 \mathrm{ab}$ & $13,3 \mathrm{a}$ \\
\hline Taper & $3,3 \mathrm{a}$ & $4,2 \mathrm{a}$ & $6,7 \mathrm{ab}$ & $9,2 \mathrm{a}$ & $10,8 \mathrm{a}$ & $12,5 \mathrm{a}$ & $13,3 \mathrm{a}$ \\
\hline Mister & $5,0 \mathrm{a}$ & $11,7 \mathrm{a}$ & $16,7 \mathrm{~b}$ & $18,3 \mathrm{a}$ & $20,0 \mathrm{a}$ & $25,8 \mathrm{~b}$ & $27,5 \mathrm{~b}$ \\
\hline Perkoz & $1,7 \mathrm{a}$ & $20,8 \mathrm{a}$ & $8,3 \mathrm{ab}$ & $9,2 \mathrm{a}$ & $10,8 \mathrm{a}$ & $12,5 \mathrm{a}$ & $12,5 \mathrm{a}$ \\
\hline Baryt & $5,0 \mathrm{a}$ & $6,7 \mathrm{a}$ & $8,3 \mathrm{ab}$ & $9,2 \mathrm{a}$ & $11,7 \mathrm{a}$ & $12,5 \mathrm{a}$ & $13,3 \mathrm{a}$ \\
\hline
\end{tabular}

Wartości w kolumnach oznaczone tą samą literą nie różnią się istotnie - Values in columns marked with the same letters do not differ significantly

mienny skład chemiczny roślin poszczególnych odmian, który determinuje intensywność żerowania ślimaków, a w rezultacie wielkość uszkodzeń roślin. Według niektórych autorów, wysoka zawartość alkaloidów (> 1,0\% s.m.), występujących w gorzkich odmianach łubinów (Lupinus polyphyllus, L. mutabilis, L. albus, L. angustifolius), może być odpowiedzialna za ograniczanie ich uszkodzeń przez ślimaki (Wink 1984; Carey i Wink 1994; Aguiar i Wink 1999, 2005; Chevalier i wsp. 2000). Wszystkie badane odmiany L. luteus charakteryzowały się jednak niską zawartością alkaloidów $(0,015-0,023 \%)$, co sugeruje, że związki te nie miały decydującego wpływu na stopień ich uszkodzenia przez ślimaki. Można przypuszczać, że w przypadku tych roślin, deterentne działanie na ślimaki 
miały inne wtórne metabolity roślinne lub właściwości fizyczne roślin. Wyjaśnienie tego mechanizmu wymaga wykonania odrębnych badań.

Stwierdzono także, że poziom uszkodzenia niektórych odmian łubinu żółtego przez A. vulgaris i $A$. rufus zdecydowanie się różni. A. vulgaris silnie uszkadzał rośliny łubinu odmiany Lord, w porównaniu do roślin łubinu odmiany Dukat. W przypadku $A$. rufus wielkości uszkodzeń roślin tych odmian były odwrotne. Wskazuje to, że $A$. vulgaris i $A$. rufus charakteryzują się różnymi preferencjami pokarmowymi w stosunku do odmian łubinu żółtego. Potwierdza to doniesienia innych autorów, na temat różnych wymagań pokarmowych i różnych reakcji poszczególnych gatunków ślimaków na rodzaj pokarmu roślinnego (Hanley i wsp. 1995; Cook i wsp. 1996; Frank i Friedli 1999; Kozłowski i Kozłowska 2009).

\section{Wnioski / Conclusions}

1. Niektóre odmiany łubinu żółtego charakteryzują się różną wrażliwością na żerowanie ślimaków $A$. vulgaris i $A$. rufus oraz na powodowane przez nie uszkodzenia roślin. W przypadku D. reticulatum poziom uszkodzeń większości odmian był podobny.

2. Ślimaki $A$. vulgaris i $A$. rufus mają zróżnicowane preferencje pokarmowe w stosunku do poszczególnych odmian łubinu żółtego.

3. Uzyskane wyniki badań mogą być potencjalnie przydatne $\mathrm{w}$ doborze odmian łubinu żółtego do uprawy na obszarach zasiedlonych przez ślimaki.

\section{Literatura / References}

Aguiar R., Wink M. 1999. Mollusc-deterrent activity of lupin alkaloids. p. 97-98. Proceeding 9th International Lupin Conference. Klink/Mültriz, “International Lupin Association”. New Zeeland, Canterbury, June 20-24, 1999, 481 pp.

Aguiar R., Wink M. 2005. How do slugs cope with toxic alkaloids? Chemoecology 15 (3): 167-177.

Barlow S.E., Close A.J., Port G.R. 2013. The acceptability of meadow plants to the slug Deroceras reticulatum and implications for grassland restoration. Annals of Botany 112 (4): 721-730.

Byers R.A. 2002. Agriolimacidae and Arionidae as pests in lucerne and other legumes in forage systems of north-eastern North America. p. 325-335. In: "Molluscs as Crop Pests" (G.M. Barker, ed.). Landcare Research Hamilton New Zealand, CABI Publishing, UK, 468 pp.

Carey D.B., Wink M. 1994. Elevational variation of quinolizidine alkaloid contents in a lupin (Lupinus argentens) of the Rocky Mountains. Journal of Chemical Ecology 20 (4): 849-857.

Chevalier L., Desbuquois C., Papineau J., Charrier M. 2000. Influence of the quinolizidine alkaloid content of Lupinus albus (Fabaceae) on the feeding choice of Helix aspersa (Gastropoda: Pulmonata). Journal of Molluscan Studies 66 (1): 61-68.

Cook R.T., Bailey S.E.R., McCrohan C.R. 1996. Slug preference for winter wheat cultivars and common agricultural weeds. Journal of Applied Ecology 33 (4): 866-872.

Domański P.J., Osiecka A. 2014. Pastewne. s. 105-135. W: „Lista opisowa odmian roślin rolniczych 2014. Burak, ziemniak, oleiste i włókniste pastewne" (E.S. Gacek, red.). COBORU, Słupia Wielka, 146 ss.

Ferguson A.W. 1994. Pests and plant injury on lupins in the south of England. Crop Protection 13 (3): 201-210.

Frank T., Friedli J. 1999. Laboratory food choice trials to explore the potential of common weeds to reduce slug feeding on oilseed rape. Biological Agriculture and Horticulture 17 (1): 19-29.

Hanley M.E., Fenner M., Edwards P.J. 1995. The effect of seedling age on the likelihood of herbivory by the slug Deroceras reticulatum. Functional Ecology 9: 754-759.

Kozłowski J., Kozłowska M. 2009. Palatability and consumption of 95 species of herbaceous plants and oilseed rape for Arion lusitanicus Mabille, 1868. Journal of Conchology 40 (1): 79-90.

South A. 1992. Terrestrial Slugs: Biology, Ecology, and Control. Chapman and Hall, London, 444 pp.

Wink M. 1984. Chemical defense of lupins. Mollusc-repellent properties of quinolizidine alkaloids. Zeitschrift für Naturforschung 39c: 553-558. 